\title{
When mutations meet motivations: Attitude biases in counterfactual thought
}

\author{
Matthew T. Crawford ${ }^{\mathrm{a}, *}$ and Sean M. McCrea ${ }^{\mathrm{b}}$ \\ ${ }^{a}$ Department of Experimental Psychology, University of Bristol, 8 Woodland Road, Bristol BS8 1TN, UK \\ ${ }^{\mathrm{b}}$ Indiana University, Bloomington, USA
}

\begin{abstract}
The present research examines whether existing attitudes can spontaneously bias the content and direction of generated counterfactual thoughts, and whether these thoughts influence subsequent attitude-relevant judgments. Two experimental studies demonstrate that attitudes can bias the content of counterfactual thoughts, and that these biased thoughts in turn predict polarized attitudes. These effects were obtained regardless of whether explicit instructions for counterfactual generation were given. Furthermore, both studies demonstrate that these effects are mediated by judgments of future likelihood. Implications of these results for theories of counterfactual thinking and persuasion are discussed.
\end{abstract}

(C) 2003 Elsevier Science (USA). All rights reserved.

Keywords: Attitudes; Bolstering; Resistance; Counterfactuals; Attribution; Perception

A great many people think they are thinking when they are merely rearranging their prejudices (William James).

People often contemplate the past, mulling over lessons to be learned. However, it is clear that individuals will not always agree what these lessons are. The implications history has for us are, at least in part, determined by our own hopes and convictions. The present research suggests that counterfactual thoughts (i.e., thoughts concerning how an event could have happened differently) are an important aspect of this biased thinking. Specifically, we propose that individuals spontaneously generate counterfactuals that are influenced by their attitudes. Furthermore, we argue that these biased counterfactual thoughts reinforce existing attitudes by altering judgments of future likelihood. In other words, these biased thoughts about the past are likely to make events that support our view seem more likely to occur, and events that contradict our view seem less likely to occur. As a result, attitudes are unlikely to change.

\footnotetext{
${ }^{*}$ Corresponding author. Fax: +44-117-928-8588.

E-mail address: m.crawford@bristol.ac.uk (M.T. Crawford).
}

\section{Attitude polarization}

Past research has shown that attitudes can influence judgments and memory in a manner that reinforces the pre-exiting attitude (Fazio, Roskos-Ewoldsen, \& Powell, 1994; Hastorf \& Cantril, 1954; Lord, Ross, \& Lepper, 1979). For example, Lord et al. (1979) presented individuals with two contradictory studies on the effectiveness of capital punishment as a deterrent to crime. Rather than leading to more moderate views, individuals were even more convinced of their original opinion after reading the studies. Subsequent research has consistently shown that individuals are likely to be more critical of unwanted information (Biek, Wood, \& Chaiken, 1996; Ditto \& Lopez, 1992; Houston \& Fazio, 1989).

Attitudes also bias judgments about the implications of the past for the future. Plous (1991) asked individuals classified as either pro- or anti-nuclear weapons to read descriptions about accidents that "almost" lead to nuclear war between the United States and the Soviet Union. After reading about these accidents, individuals with anti-nuclear views indicated they believed more strongly that an inadvertent nuclear war 
could occur in the future. However, individuals with pro-nuclear views indicated they believed more strongly that an inadvertent nuclear war would not occur in the future. Supporters of nuclear weapons cited the effectiveness of safeguards as the primary determinant of assessing nuclear risk, whereas detractors cited the fact that the accident occurred at all. Thus, individuals with opposing views focused on different aspects of the events, and as a result, were likely to have different views about the likelihood of similar events happening in the future (Plous, 1991). Counterfactual thinking may play an important role in these effects.

\section{Counterfactual thoughts}

Counterfactual thoughts are a key determinant of individuals' judgments about the past. These thoughts identify how an event could have happened differently by mutating antecedent conditions. Counterfactual thoughts can be upward (i.e., how an event could have been better) or downward (i.e., how an event could have been worse). An important function of counterfactual thinking is that mutated aspects of the event are seen as causal factors (Mandel \& Lehman, 1996; Wells \& Gavanski, 1989). Which aspect of an event is mutated thus has far-reaching consequences for attributions and blame, emotions, coping, and future behavior (Roese, 1997). Therefore, an important focus of counterfactual research has been to identify determinants of the mutation of antecedents.

Counterfactual reasoning is likely to be both datadriven and theory-driven (Kahneman \& Miller, 1986; Tetlock, 1998). However, much of the extant research and theory has focused on the data-driven aspects of counterfactual mutation. For example, according to norm theory (Kahneman \& Miller, 1986), antecedents of events that are seen as nonnormal or unexpected are likely to make counterfactual thoughts more available. Negative outcomes are also likely to evoke greater counterfactual scrutiny (Sanna \& Turley, 1996), as are controllable antecedents (Mandel \& Lehman, 1996; Markman, Gavanski, Sherman, \& McMullen, 1995) and actions (Kahneman \& Miller, 1986; Landman, 1987).

Recent research has begun to examine more theorybased or motivated counterfactual reasoning. The most extensive research on the topic of attitude biases in counterfactual thinking has been conducted by Tetlock (1998) and Tetlock and Visser (2000). They argue that beliefs, expectancies, and attitudes are likely to influence counterfactual thinking in a theory-driven manner. Tetlock (1998) conducted two studies demonstrating that participants rejected counterfactuals that challenged an established world-view. A subsequent study showed that participants also embraced counterfactuals that made incorrect predictions about historical events seem "almost right." Similarly, Tetlock and Visser (2000) asked experts on the Soviet Union to judge the plausibility of counterfactual statements about Russian history. Consistent with the view that attitudes can bias counterfactual thinking, the judged plausibility of these statements was predicted by political ideology, and, in turn, predicted a number of policy preferences.

Thus, it is clear that counterfactual reasoning is impacted significantly by pre-existing views, and that individuals prefer thoughts that support these beliefs rather than refute them. We wished to take these ideas a step further. Specifically, we sought to examine whether attitudes spontaneously bias the generation of counterfactual thoughts, and explain how counterfactual thoughts might reinforce subsequent attitudes.

\section{Bias in generated thoughts}

Despite the evidence of attitudinal biases in the acceptability of counterfactual thinking presented by Tetlock (1998) and Tetlock and Visser (2000), there has been little work concerning whether motivations can bias which antecedents of an event are mutated, and the findings of these studies are often contradictory. For example, Roese and Olson (1993) found that high self-esteem individuals mutated external factors following failures, but internal factors following success, consistent with self-serving attributional patterns (e.g., McFarland \& Ross, 1982; Miller, 1976). However, Branscombe, N'gbala, Kobrynowicz, and Wann (1997) failed to find evidence of such self-serving mutations. They argue that individuals tend to mutate antecedents about which they have more knowledge (e.g., the self or ingroup). Similarly, Burris and Branscombe (1993) did not find evidence that prejudice influenced mutations of a target's actions when race information was varied. Branscombe et al. (1997) argue that accessibility drives what is mutated, automatically and outside awareness. As a result, they argue that motivation may not exert any influence on what is mutated.

Thus, although Tetlock (1998) and Tetlock and Visser (2000) have shown a link between attitudes and the acceptability of counterfactual thoughts, the question of whether attitudes influence counterfactual generation remains open. Furthermore, the question of whether these biases occur spontaneously is an important one. Many studies of counterfactual thinking (e.g., Branscombe et al., 1997; Markman et al., 1995) have provided participants with detailed instructions and examples of counterfactual constructions. However, it is possible that individuals do not generate such thoughts without prompting, and these instructions might alter behavior. Thus, the present set of studies 
examine the spontaneity of such biased thoughts in reaction to an event.

A second important aspect of the present research is determining the process by which counterfactual thoughts reinforce attitudes. We propose that counterfactuals will heavily impact judgments of future likelihood, and that these judgments will in part determine the consequences of an outcome for attitudes. Counterfactual thoughts might underlie the effects attitudes on future likelihood judgments demonstrated by Plous (1991). Research has already shown that counterfactual thoughts can influence judgments of past likelihood (Roese \& Olson, 1996). Similar effects are likely to occur for future probabilities as well. We propose that likelihood judgments mediate the effects of counterfactual thinking on subsequent attitudes.

\section{Study 1}

Study 1 examined whether attitudes bias the content of generated counterfactual thoughts, and whether these biased thoughts reinforce the original attitude via judgments of future likelihood. To examine these issues, we had participants read a scenario concerning waiting periods for gun purchases. The outcome of the event was manipulated such that a negative outcome occurred or was narrowly averted. To determine the spontaneity of attitude biases, we manipulated instruction set (i.e., guided or open-ended) for counterfactual generation (see also Sanna, 1996; Sanna \& Turley, 1996). We predicted that attitudes would bias counterfactual thoughts regardless of instruction set or outcome.

\section{Method}

\section{Participants and design}

Participants were 179 students from an introductory psychology course at Indiana University. The design of the study was a 2 (Outcome: positive vs. negative) $\times 2$ (Instructions: open-ended vs. guided) factorial with attitudes allowed to vary.

\section{Scenario}

Participants read about a woman named D.L. who was being stalked by a coworker. They read that, until the man actually broke a law, the police could not arrest him. D.L. decided to buy a gun, but had to wait 5-days before she could purchase it. The scenario had one of two possible outcomes. In the positive outcome condition, D.L. purchased the gun and the same night was attacked by the man in her home. D.L. shot the man in the leg and he was arrested. In the negative outcome condition, D.L. was attacked the night before she was able to purchase the gun and was killed.

\section{Procedure}

Participants first completed an attitude questionnaire that asked participants about a variety of social issues. One of these items concerned waiting periods for gun purchases. Participants expressed their agreement with the following statement: "The five-day waiting period on purchasing a gun is a good idea." Participants responded using a seven-point scale ranging from 1 (strongly disagree) to 7 (strongly agree).

After completing the attitude measure, participants read another unrelated scenario. They were then randomly assigned to read one of the D.L. scenarios. After reading the scenario, participants were given instructions concerning counterfactual generation. Participants in the open-ended instruction condition were asked to list their thoughts about the scenario. Those in the guided instruction condition were given a description of both upward and downward comparisons, with examples of counterfactuals unrelated to the current issue. After listing their thoughts, participants responded to questions concerning the scenario. Participants indicated how typical they thought D.L.'s case was, and how likely it would be for such an event to occur again. Participants responded using a seven-point scale ranging from -3 (not at all) to 3 (very much). Finally, participants were asked whether they felt the waiting period for a gun purchase should be shorter, the same, or longer (scale ranging from -3 (shorter) to 3 (longer)).

\section{Results and discussion}

\section{Overview}

Regression analyses were utilized due to the continuous nature of the attitude data. Unweighted effects coding was used for the dichotomous variables and the attitude variable was mean-centered. Significant interactions were probed using simple-slope tests with dummy coding for dichotomous variables. For continuous variables, these tests were performed one-standard deviation below and above the mean (cf., Aiken \& West, 1991).

\section{Counterfactual thoughts}

Two condition-blind assistants coded thoughts into one of five content categories: (a) waiting period law, (b) police, (c) victim, (d) perpetrator, and (e) miscellaneous thoughts. Coders also classified the direction of each counterfactual thought. Preliminary analyses examined the correlation between initial attitude and number of upward and downward thoughts in each category. These analyses revealed that attitude most strongly related to upward counterfactual thoughts about the law and upward counterfactual thoughts about the victim. To simplify the presentation of the results, a single index of counterfactual Focus was created by subtracting the 
number of upward thoughts about the victim from the number of upward thoughts about the law. Higher numbers therefore indicate a relative focus on mutating aspects of the waiting period law compared to D.L.'s actions.

A regression model was then utilized to predict the relative emphasis on the law or the victim's actions. Outcome, Instruction, and Attitude were entered as a first step, all two-way interactions of these variables as a second step, and the three-way interaction as a final step. The only significant effect was the Attitude term ( $\beta=-.187, t=-2.44, p<.05)$, indicating that individuals in favor of waiting periods for gun purchases were more likely to mutate aspects of D.L.'s actions, whereas individuals opposed to waiting periods were more likely to mutate the waiting period law. As predicted, attitudes biased counterfactual generation regardless of outcome or instruction set Table 1.

\section{Subsequent attitude}

To examine the relationship between counterfactual thoughts and subsequent attitude, the counterfactual Focus variable and all interactions of this variable with Outcome, Instruction, and Attitude were added to the regression model as a fourth step (see Table 2). Attitude predicted judgments of whether there should be shorter or longer waiting periods for gun purchases. This effect was qualified by an interaction of Attitude $\times$ Outcome.

Table 1

Correlations Study 1

\begin{tabular}{|c|c|c|c|c|}
\hline & $\begin{array}{l}\text { Initial } \\
\text { attitude }\end{array}$ & Focus & Likelihood & $\begin{array}{l}\text { Subsequent } \\
\text { attitude }\end{array}$ \\
\hline Initial attitude & - & & & \\
\hline Focus & $-.20^{\dagger}$ & - & & \\
\hline Likelihood & $-.17^{*}$ & -.04 & - & \\
\hline $\begin{array}{l}\text { Subsequent } \\
\text { attitude }\end{array}$ & $.31^{\ddagger}$ & -.08 & $-.30^{\ddagger}$ & - \\
\hline
\end{tabular}

Note. ${ }^{*} p<.05 ;{ }^{\dagger} p<.01 ;{ }^{\ddagger} p<.001$.
This interaction revealed that the Attitude effect was stronger in the positive outcome condition (simpleslope $=.375, t=4.15, p<.001)$ than in the negative outcome condition (simple-slope $=.192, \quad t=2.34$, $p<.05)$.

In addition, the Focus $\times$ Outcome interaction approached significance. As predicted, those in the negative condition who counterfactualized the law more than D.L.'s actions believed that there should be a shorter waiting period (simple-slope $=-.247, t=2.31, p<.05$ ). However, this effect was not found in the positive outcome condition (simple-slope $=.308, t=1.80, p=.08$ ).

Finally, the Focus $\times$ Attitude $\times$ Instruction interaction was significant. The effect of Focus was significant for individuals in favor of the waiting period when in the guided instruction condition (simple-slope $=.335$, $t=1.94, p<.06$ ), indicating that a greater focus on mutating D.L.'s actions lead to believing the waiting period should be shorter. There were no other effects of Focus (all slopes $<.191, t \mathrm{~s}<1.10, n s$ ). This finding is contrary to our prediction that focusing on the victim's actions would lead to believing that the waiting period should be longer. In all other cases, those initially in favor of the waiting period believed the waiting period should be longer.

\section{Mediational results}

The typicality and likelihood ratings were strongly correlated $(r=.65)$, and so these measures were summed to create a combined measure of perceived likelihood $(\alpha=.74)$. The model predicting likelihood was the same as for predicting subsequent attitude (see Table 3).

On the combined measure of likelihood, there was an effect of Outcome, indicating that individuals believed D.L.'s case was less likely to reoccur in the positive condition. In addition, the effect of Focus $\times$ Attitude was significant. Consistent with our predictions, individuals who were initially against the waiting period believed this type of case was more likely to reoccur

Table 2

Mediational results for Study 1

\begin{tabular}{|c|c|c|c|c|c|c|}
\hline \multirow[t]{2}{*}{ Terms } & \multicolumn{3}{|c|}{ Initial model } & \multicolumn{3}{|c|}{ Mediational model } \\
\hline & $\beta$ & $t$ & $p$ & $\beta$ & $t$ & $p$ \\
\hline Attitude & .254 & 3.18 & $<.01$ & .233 & 2.94 & $<.01$ \\
\hline Outcome & -.129 & -1.81 & .07 & -.086 & -1.18 & $n s$ \\
\hline Instruction & .046 & $<1$ & $n s$ & .069 & $<1$ & $n s$ \\
\hline Focus & .085 & $<1$ & $n s$ & .065 & $<1$ & $n s$ \\
\hline Attitude $\times$ Outcome & .181 & 2.28 & $<.05$ & .160 & 2.02 & $<.05$ \\
\hline Attitude $\times$ Instruction & .069 & $<1$ & $n s$ & .058 & $<1$ & $n s$ \\
\hline Focus $\times$ Attitude & .104 & $<1$ & $n s$ & .064 & $<1$ & $n s$ \\
\hline Focus $\times$ Outcome & .171 & 1.92 & .05 & .144 & 1.62 & $n s$ \\
\hline Focus $\times$ Instruction & -.067 & $<1$ & $n s$ & -.057 & $<1$ & $n s$ \\
\hline Focus $\times$ Attitude $\times$ Instruction & -.243 & -2.12 & $<.05$ & -.222 & -1.96 & .05 \\
\hline Likelihood & & & & -.174 & -2.31 & $<.05$ \\
\hline
\end{tabular}

Note. Only significant effects and lower order terms of significant interactions are presented. 
Table 3

Effects on combined likelihood ratings for Study 1

\begin{tabular}{llrl}
\hline \multirow{2}{*}{ Terms } & \multicolumn{2}{l}{ Likelihood } & \multicolumn{1}{l}{} \\
\cline { 2 - 4 } & $\beta$ & $t$ & $n s$ \\
\hline Attitude & -.121 & -1.48 & $<.01$ \\
Outcome & .247 & 3.38 & $n s$ \\
Focus & -.117 & -1.29 & $<.05$ \\
Attitude $\times$ Focus & -.232 & -2.00 & $<$ \\
\hline
\end{tabular}

Note. Only significant effects and lower order terms of significant interactions are presented.

when generating counterfactuals about the law more than about the victim (simple-slope $=-.583, t=-1.80$, $p=.07)$. There was no effect of counterfactual Focus among those in favor of the waiting period (simpleslope $=.183, t<1, n s$ ).

Mediational analyses. We predicted that likelihood judgments would mediate the relationship between counterfactual thinking and subsequent attitude, such that counterfactuals related to lower judgments of future likelihood would predict stronger belief in having longer waiting periods. To test this mediational hypothesis, three steps must be satisfied (Judd \& Kenny, 1981). First, the independent/predictor variable (counterfactual thoughts) must predict the dependent variable (subsequent attitude). These findings are presented above. Second, the independent variable must predict the proposed mediator (likelihood). As shown above, the interaction of counterfactual thoughts and initial attitude predicted the combined likelihood ratings. Finally, the proposed mediating variable must predict the dependent variable while statistically controlling for the independent variables. The addition of the mediating variable must eliminate the effects of the independent variable in order to claim that the mediator completely explains the effects of the independent variable. Therefore, we added the combined likelihood rating as a final step to the model predicting subsequent attitude. Likelihood did predict subsequent attitude, even when controlling for counterfactual Focus (Table 2). Viewing the

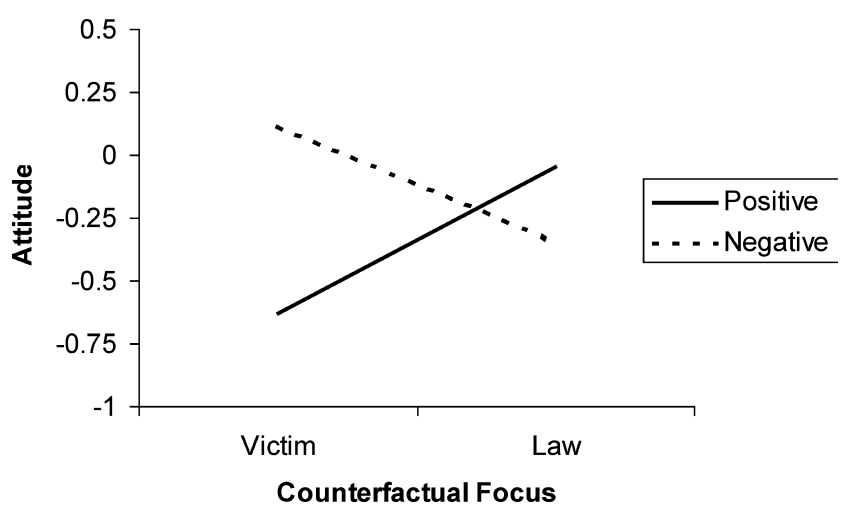

Fig. 1. Study 1: counterfactual Focus $\times$ Outcome interaction. Subsequent attitude towards waiting period. event as more likely related to judgments that shorter waiting periods are needed. The addition of the likelihood term eliminated the effect of Focus $\times$ Outcome and reduced the Focus $\times$ Attitude $\times$ Instruction effect. These findings are evidence for mediation of the effects of attitude-induced counterfactual bias on subsequent attitude by likelihood judgments (see Fig. 1).

\section{Study 2}

Study 2 sought to replicate these effects with a different attitude topic: capital punishment. This domain was chosen as an example where politically conservative individuals would be challenged by a negative event whereas gun control most likely challenged the attitudes of politically liberal individuals. Therefore, we conducted a second study using the same basic procedures. We again predicted that attitudes would spontaneously bias counterfactual thoughts, and that the counterfactual thoughts would reinforce existing attitudes via judgments of future likelihood.

\section{Method}

\section{Participants and design}

Participants were 191 introductory psychology students at Indiana University. The design was parallel to Study 1 .

\section{Scenario}

Participants read about a man named T.B., who was on death row for killing two people in a robbery. T.B. maintained his innocence, but lost five appeals and did not receive a pardon. He hired a new lawyer to help him. Two possible outcomes occur. In the positive condition, the new lawyer found evidence proving that T.B. was innocent and secured his release. In the negative condition, the lawyer found the new evidence one month after T.B. was executed.

\section{Procedure}

The procedure was identical to Study 1. Among the attitude measures was an item assessing attitudes towards the number of appeals in capital punishment cases. Participants indicated their agreement with the following statement: "People convicted of capital crimes are given too many appeals."

Participants again read a filler scenario, followed by the critical scenario. They were then given one of two types of instructions and listed their thoughts. Participants indicated how typical they thought the case was and how likely it would be for such an event to occur again. Participants were asked whether they felt the number of appeals in capital punishment cases should be fewer, the same, or more. 
Results $^{1}$

\section{Counterfactual thoughts}

Coders categorized counterfactual thoughts into several content areas: (a) capital punishment and the number of appeals, (b) T.B.'s lawyers, (c) police, (d) T.B.'s actions, and (e) a miscellaneous category. Preliminary analyses revealed that attitude was correlated only with the total number of thoughts about the law. Initial Attitude, Outcome, and Instruction were entered into the model predicting these thoughts as a first step, followed by all two-way interactions as a second step, and the three-way interaction as a final step.

For thoughts concerning capital punishment and the number of appeals, significant effects of Outcome $(\beta=-.119, t=-1.82, p=.07)$ and Instruction $(\beta=$ $-.377, t=-5.75, p<.001)$, were qualified by a significant interaction of Outcome $\times$ Instruction $(\beta=.178$, $t=2.71, p<.01)$. Individuals made more counterfactual thoughts concerning capital punishment under the guided instructions, particularly when the outcome was negative (simple-slope $=-.703, t=-5.83, p<.001$ ), rather than positive (simple-slope $=-.290, t=-2.38$, $p<.05$ ) (see Table 4).

More importantly, the effect of Attitude $(\beta=-.126$, $t=-1.92, p=.06)$ indicated that those who believed there are too many appeals in capital punishment cases made fewer counterfactuals about capital punishment and the number of appeals. This effect was qualified by an Attitude $\times$ Instruction interaction $(\beta=.135$, $t=2.05, p<.05)$. This interaction revealed that the Attitude effect was stronger in the guided instruction condition (simple-slope $=-.090, \quad t=-2.41, \quad p<.05$ ) than in the open-ended instruction condition (simpleslope $=-.003, t<1, n s$ ). Thus, attitude bias in counterfactual generation did not appear to be spontaneous in Study 2 .

\section{Subsequent attitude}

Focus and all interactions of this variable with Outcome, Attitude, and Instruction were added to the model predicting subsequent attitude as a final step (see Table 5). Significant effects of Outcome and Focus were obtained, over and above the effect of the initial Attitude. These effects were qualified by significant interactions of Focus $\times$ Outcome and Focus $\times$ Attitude (see Figs. 2 and 3, respectively).

Probes revealed that individuals who made more counterfactuals concerning capital punishment tended to believe that more appeals were needed in the negative outcome condition (simple-slope $=.241, \quad t=1.38$, $p=.17$ ), but not the positive outcome condition (simple-slope $=-.159, t<1, n s$ ).

\footnotetext{
${ }^{1}$ Regression analyses were the same as for Study 1.
}

Table 4

Correlations for Study 2

\begin{tabular}{lclll}
\hline & $\begin{array}{l}\text { Initial } \\
\text { attitude }\end{array}$ & Focus & Likelihood & $\begin{array}{l}\text { Subsequent } \\
\text { attitude }\end{array}$ \\
\hline Initial attitude & - & & & \\
Focus & $-.14^{*}$ & - & & \\
Likelihood & .01 & $-.17^{*}$ & - & - \\
$\begin{array}{l}\text { Subsequent } \\
\text { attitude }\end{array}$ & $-.34^{\ddagger}$ & -.06 & $.30^{\ddagger}$ & - \\
\hline Note. ${ }^{*} p<.05 ;{ }^{\ddagger} p<.001$. & & &
\end{tabular}

Those participants that initially agreed that there are too many appeals were more convinced of this viewpoint when they made more capital punishment counterfactuals (simple-slope $=-.576, t=-2.79, p<.01$ ), whereas those that initially believed that there are not too many appeals were more convinced that more appeals are needed when they made more capital punishment counterfactuals (simple-slope $=.349, \quad t=2.26$, $p<.05)$. The same counterfactual thoughts predicted reinforced initial beliefs for both sides of this issue.

These results again demonstrate that counterfactual thoughts polarized subsequent attitudes about appeals, particularly when the outcome was negative. In addition, these effects held regardless of instruction set.

\section{Mediational results}

The likelihood and typicality ratings were strongly correlated $(r=.60)$ and so were summed to create a single measure $(\alpha=.79)$. The model used to predict the combined likelihood rating was the same as that used for subsequent attitude (see Table 6). The Attitude $\times$ Instruction interaction was significant, indicating that those initially supporting the number of appeals tended to think T.B.'s case was less likely to reoccur in the open-ended instruction condition (simple-slope $=$ $-.189, t=-1.03, n s$ ), and more likely to reoccur in the guided-instruction condition (simple-slope $=.231, t=$ $1.25, p=n s$ ), although neither effect reached significance.

The Focus $\times$ Instruction interaction revealed that those generating counterfactuals about the law thought T.B.'s case was less likely to reoccur in the guided-instruction condition (simple-slope $=-1.001, t=-2.46$, $p<.05)$, but not in the open-ended instruction condition (simple-slope $=-.351, t<1, n s$ ).

Finally, the Attitude $\times$ Focus $\times$ Outcome interaction was significant. Those who initially believed there are too few appeals tended to view the case as less typical when they had made more counterfactuals concerning capital punishment and when the outcome was positive ( simple-slope $=-2.095, t=-3.32, p<.001$ ), but not when the outcome was negative (simple-slope $=-.077$, $t<1, n s)$. Those who initially believed there are too many appeals tended to view T.B.'s case as less typical when they had made more counterfactuals concerning 
Table 5

Mediational results for Study 2

\begin{tabular}{|c|c|c|c|c|c|c|}
\hline \multirow[t]{2}{*}{ Terms } & \multicolumn{3}{|c|}{ Initial model } & \multicolumn{3}{|c|}{ Mediation model } \\
\hline & $\beta$ & $t$ & $p$ & $\beta$ & $t$ & $p$ \\
\hline Attitude & -.303 & -2.60 & $<.01$ & -.276 & -2.54 & $<.05$ \\
\hline Outcome & -.175 & -2.08 & $<.05$ & -.150 & -1.91 & .06 \\
\hline Instruction & .060 & $<1$ & $n s$ & .048 & $<1$ & $n s$ \\
\hline Focus & -.072 & $<1$ & $n s$ & -.036 & $<1$ & $n s$ \\
\hline Attitude $\times$ Outcome & -.111 & $<1$ & $n s$ & -.147 & -1.35 & $n s$ \\
\hline Attitude $\times$ Instruction & -.028 & $<1$ & $n s$ & .057 & $<1$ & $n s$ \\
\hline Outcome $\times$ Instruction & -.100 & -1.19 & $n s$ & -.101 & -1.29 & $n s$ \\
\hline Focus $\times$ Attitude & -.280 & -1.86 & .06 & -.147 & -1.35 & $n s$ \\
\hline Focus $\times$ Outcome & -.240 & -2.37 & $<.05$ & -.239 & -2.53 & $<.05$ \\
\hline Attitude $\times$ Outcome $\times$ Instruction & -.149 & -1.28 & $n s$ & -2.18 & -2.00 & $<.05$ \\
\hline Focus $\times$ Attitude $\times$ Outcome & -.012 & $<1$ & $n s$ & -.265 & -1.83 & .07 \\
\hline Likelihood & & & & .343 & 5.16 & $<.001$ \\
\hline
\end{tabular}

Note. Only significant effects and lower order terms of significant interactions are presented.

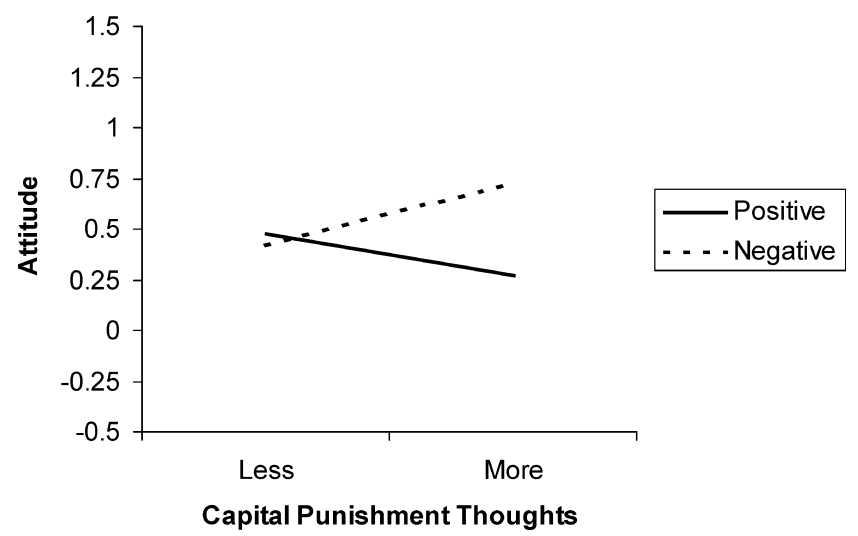

Fig. 2. Study 2: counterfactual Focus $\times$ Outcome interaction. Subsequent attitude towards number of appeals.

the law and when the outcome was negative (simpleslope $=-1.529, t=-2.29, p<.05)$, but not when it was positive (simple-slope $=.688, t<1, n s$ ).

Mediational analyses. As in Study 1, we predicted that the likelihood ratings would mediate the effects of counterfactual thinking on subsequent attitude, such that counterfactuals related to lower ratings of future likelihood would predict stronger belief in having fewer appeals.

We demonstrated that the independent/predictor variable (counterfactual Focus) predicted the dependent variable (subsequent attitude), and that the independent variable predicted the proposed mediator (likelihood). To examine whether the mediating variables predicted the dependent variable while statistically controlling for the independent variable, we again added combined likelihood ratings as a final step to the model predicting subsequent attitude. As can be seen in Table 5 , likelihood ratings did predict subsequent attitude, even while controlling for counterfactual Focus. Viewing the event as more likely predicted judgments that more appeals are needed. The addition of the likelihood

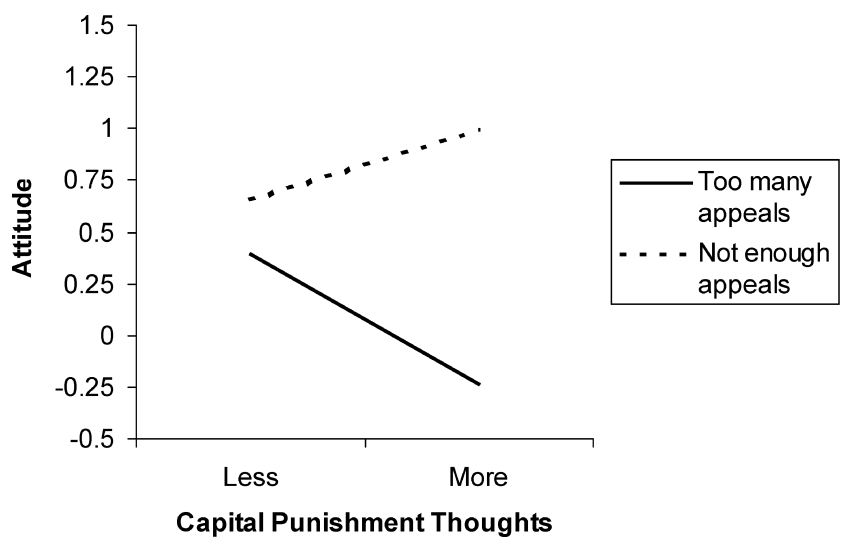

Fig. 3. Study 2: counterfactual Focus $\times$ Initial attitude interaction. Subsequent attitude towards number of appeals.

term eliminated the Focus $\times$ Attitude interaction. As in Study 1 , these findings are evidence for mediation of the effects of attitude-induced counterfactual bias by likelihood ratings, and explained the effect of counterfactual Focus on subsequent attitude.

Table 6

Effects on combined likelihood ratings for Study 2

\begin{tabular}{llll}
\hline \multirow{2}{*}{ Terms } & \multicolumn{3}{l}{ Likelihood } \\
\cline { 2 - 4 } & $\beta$ & $t$ & $p$ \\
\hline Attitude & -.078 & $<1$ & $n s$ \\
Outcome & -.073 & $<1$ & $n s$ \\
Instruction & .037 & $<1$ & $n s$ \\
Focus & -.105 & $<1$ & $n s$ \\
Attitude $\times$ Outcome & .105 & $<1$ & $n s$ \\
Attitude $\times$ Instruction & -.248 & 2.00 & $<.05$ \\
Focus $\times$ Attitude & -.183 & 1.14 & $n s$ \\
Focus $\times$ Outcome & -.003 & $<1$ & $n s$ \\
Focus $\times$ Instruction & .189 & 1.89 & .06 \\
Focus $\times$ Attitude $\times$ Outcome & .481 & 2.96 & $<.01$ \\
\hline
\end{tabular}

Note. Only significant effects and lower order terms of significant interactions are presented. 


\section{General discussion}

Past research has outlined a number of ways that individuals may defend their attitudes when faced with a counter-attitudinal, or persuasive message, such as counterarguing (Eagly \& Chaiken, 1995; McGuire, 1964), viewing the source of the argument as untrustworthy or invalid (Buller, 1986; Lord et al., 1979; Wright, 1975), asserting confidence in their own judgment (Jacks \& Cameron, in press), or responding with anger (Abelson \& Miller, 1967). These responses can be engaged in quite easily and (to varying degrees) effectively in response to a persuasive message. How do individuals respond to events that might challenge their beliefs?

The present studies suggest that counterfactual thoughts about events can also be used to defend existing attitudes. The results of the studies supported our contention that attitudes can bias counterfactual thought. Attitudes toward social issues biased both the content of generated counterfactuals (Study 1) and the number of counterfactuals generated (Study 2) in response to the scenarios. Together with the work reported by Tetlock (1998) and Tetlock and Visser (2000), the studies provide strong support for the notion that counterfactual reasoning is influenced by attitudes, and that counterfactual generation, as well as judged plausibility, can be theory-based.

We also hypothesized that generated counterfactuals would serve to bolster the original attitude via judgments of future likelihood. Attitude polarization was obtained in both studies, although evidence for attitude change was also found for some participants in Study 1. In both studies, the relationship between counterfactual focus and attitude polarization was mediated by biases in future likelihood judgments. These findings are consistent with our view that counterfactuals determine the interpretation of the causes of an event and thereby alter assessments of what needs to be done in the future. As these studies show, these judgments may often times be consistent with existing attitudes.

Finally, the results of both studies extend past research by demonstrating that attitude effects on counterfactual thinking can occur spontaneously, without guided instructions. Attitude bias in counterfactual generation was found only in the guided instruction condition in Study 2 but in both conditions in Study 1 . In addition, the influence of counterfactual focus on subsequent attitudes actually held more strongly for the open-ended instruction condition in Study 1, and had no effect in Study 2. These findings support the notion that our effects occur spontaneously. In addition, the findings held more strongly for negative outcomes than for positive outcomes. Presumably, the negative outcomes were more challenging to pre-existing attitudes. However, negative outcomes are also more likely to spur counterfactual thinking (Roese, 1997; Sanna \& Turley, 1996) and a more critical examination of the event (Ditto \& Lopez, 1992). Thus, biased processing is potentially more likely to occur when the outcome is a negative one.

\section{Implications for attitude stability and change}

The results of the current studies indicate that the biasing effects of attitudes on counterfactual generation seem to reinforce the initial attitude, making one less susceptible to unwanted persuasion. This process is similar to attitude bolstering (Cameron, Jacks, \& O'Brien, 2002; Sherman \& Gorkin, 1980), which may be the most common and effective method of resistance to a persuasive attempt (Jacks \& Cameron, in press). Our results also support past work showing that mere thought can lead to attitude polarization (cf. Tesser, Martin, \& Mendolia, 1995). The present research demonstrates yet another avenue by which thinking might strengthen existing attitudes. To provide stronger evidence of this claim, future research must determine whether counterfactual thoughts are indeed a causal factor in attitude polarization. A study manipulating the counterfactual focus of participants would provide such a test.

An interesting implication of such a role is that the focus of counterfactual mutation could serve to change, as well as reinforce, an existing viewpoint. By presenting counterfactual comparison thoughts that conflict with the initial attitude, one may bring about dissonance or even attitude change. For example, if a person is in favor of waiting periods, and is presented with plausible counterfactual thoughts that mutate the law as the cause of a negative outcome (thus challenging the initial attitude), perhaps she would be less resistant to change.

\section{Attitude accessibility}

How does one resolve the apparent discrepancy between the present studies and those of Tetlock (1998) and Tetlock and Visser (2000) demonstrating attitudinal bias and those that do not (e.g., Burris \& Branscombe, 1993). Bransombe and colleagues posit that what is mutated in a counterfactual comparison occurs rather automatically and thus is free from motivational biases. The proposed mechanism for counterfactual mutation involves familiarity, knowledge, or the expertise of the perceiver in a specific domain. In contrast, attributions of blame are proposed to occur in a more controlled fashion allowing the operation of motivational influences (Branscombe et al., 1997).

Although it has yet to be determined how automatic or controlled counterfactual thinking might be, there is ample reason to believe that motivational influences could impact the generation of these thoughts. Attitudes strong enough to be automatically activated (Bizer \& 
Krosnick, 2001; Fazio, 1990, 1995) could still impact counterfactual generation outside awareness. Furthermore, recent research has shown that goals can function nonconsciously (Bargh \& Barndollar, 1996). Thus, it is not altogether clear why the automaticity of counterfactual thinking would preclude motivational influences. Additionally, causal inferences, where such motivational biases are well documented, can be similarly nonconscious (Hassin, Bargh, \& Uleman, 2002). Thus, we view variability in the automaticity of the attitude or motivational construct, rather than the automaticity of the counterfactual process relative to attribution processes, as a moderator of these bias effects. Strongly held, or automatically activated, attitudes should influence the generation of counterfactuals, and these counterfactuals should serve to bolster the initial attitude.

Although the current experiments did not manipulate the accessibility of attitudes, it seems plausible that the issues that were chosen in the present studies, as well as those by Tetlock (1998) and Tetlock and Visser (2000) are the types of issues that elicit strong attitudes. We suspect studies that have not found evidence of these biases may have chosen participants lacking such strong beliefs. Furthermore, the conclusion that knowledge or expertise determine counterfactual reasoning (Branscombe et al., 1997; Tetlock \& Visser, 2000) may belie how well rehearsed these beliefs are. Future research certainly must address the issue of automaticity in these effects.

In conclusion, the present research contributes to the understanding of how individuals are able to retain their beliefs even in the face of conflicting evidence. Attitudes may not only color the way we see an event, but also how we think that event could have happened differently. As a result, individuals are likely to have divergent views of what should be learned from the past, and how we should best prepare for the future.

\section{Acknowledgments}

The authors share equal responsibility for this work. The authors wish to thank Ed Hirt and members of the Social Seminar at Indiana University for their helpful suggestions, as well as Gina Nidlinger and Gabe Smith who served as coders for the studies. Portions of this research were previously presented at the annual meeting of the Midwestern Psychological Society in 1999, as well as the annual meeting of the Society for Personality and Social Psychology in 2001.

\section{References}

Abelson, R. P., \& Miller, J. C. (1967). Negative persuasion via personal insult. Journal of Experimental Social Psychology, 3, $321-333$.
Aiken, L. S., \& West, S. G. (1991). Multiple regression: Testing and interpreting interactions. Thousand Oaks, CA: Sage.

Bargh, J. A., \& Barndollar, K. (1996). Automaticity in action: The unconscious as repository of chronic goals and motives. In P. M. Gollwitzer, \& J. A. Bargh (Eds.), The psychology of action: Linking cognition and motivation to behavior (pp. 457-481). New York: Guilford Press.

Biek, M., Wood, W., \& Chaiken, S. (1996). Working knowledge, cognitive processing, and attitudes: On the determinants of bias. Personality and Social Psychology Bulletin, 22, 547-556.

Bizer, G. Y., \& Krosnick, J. A. (2001). Exploring the structure of strength-related attitude features: The relation between attitude importance and attitude accessibility. Journal of Personality and Social Psychology, 81, 566-586.

Branscombe, N. R., N'gbala, A., Kobrynowicz, D., \& Wann, D. L. (1997). Self and group protection concerns influence attributions but they are not determinants of counterfactual mutation focus. British Journal of Social Psychology, 37, 387-404.

Buller, D. B. (1986). Distraction during persuasive communication: A meta-analytic review. Communication Monographs, 53, 91-114.

Burris, C. T., \& Branscombe, N. R. (1993). Racism, counterfactual thinking, and judgment severity. Journal of Applied Social Psychology, 23, 980-995.

Cameron, K. A., Jacks, J. Z., \& O'Brien, M. E. (2002). An experimental examination of strategoes for resisting persuasion. Current Research in Social Psychology, 7, 205-225.

Ditto, P. H., \& Lopez, D. F. (1992). Motivated scepticism: Use of differential decision criteria for preferred and nonpreferred conclusions. Journal of Personality and Social Psychology, 63, 568-584.

Eagly, A. H., \& Chaiken, S. (1995). Attitude strength, attitude structure, and resistance to change. In R. E. Petty, \& J. A. Krosnick (Eds.), Attitude strength: Antecedents and consequences (pp. 413-432). Hillsdale, NJ: Erlbaum.

Fazio, R. H. (1990). Multiple processes by which attitudes guide behavior: The MODE model as an integrative framework. In M. P. Zanna (Ed.), Advances in experimental social psychology: Vol. 23 (pp. 75-109). New York: Academic Press.

Fazio, R. H. (1995). Attitudes as object-evaluation associations: Determinants, consequences, and correlates of attitude accessibility. In R. E. Petty, \& J. A. Krosnick (Eds.), Attitude strength: Antecedents and consequences (pp. 247-282). Hillsdale, NJ: Erlbaum.

Fazio, R. H., Roskos-Ewoldsen, D. R., \& Powell, M. C. (1994). Attitudes, perception, and attention. In P. M. Niedenthal, \& S. Kitayama (Eds.), The heart's eye: Emotional influences in perception and attention (pp. 197-216). New York: Academic Press.

Hassin, R. R., Bargh, J. A., \& Uleman, J. S. (2002). Spontaneous causal inferences. Journal of Experimental Social Psychology, 38, 515-522.

Hastorf, A. H., \& Cantril, H. (1954). They saw a game: A case study. Journal of Abnormal and Social Psychology, 49, 129-134.

Houston, D. A., \& Fazio, R. H. (1989). Biased processing as a function of attitude accessibility: Make objective judgments subjectively. Social Cognition, 7, 51-66.

Jacks, J. Z., Cameron, K. A., (in press). Strategies for resisting persuasion. Basic and Applied Social Psychology.

Judd, C. M., \& Kenny, D. A. (1981). Process analysis: Estimating mediation in treatment evaluations. Evaluation Review, 5, 602-619.

Kahneman, D., \& Miller, D. T. (1986). Norm theory: Comparing reality to its alternatives. Psychological Review, 93, 136-153.

Landman, J. (1987). Regret and elation following action and inaction: Affective responses to positive versus negative outcomes. Personality and Social Psychology Bulletin, 13, 524-536.

Lord, C. G., Ross, L., \& Lepper, M. R. (1979). Biased assimilation and attitude polarization: The effects of prior theories on subsequently considered evidence. Journal of Personality and Social Psychology, 37, 2098-2109. 
Mandel, D. R., \& Lehman, D. R. (1996). Counterfactual thinking and ascriptions of cause and preventability. Journal of Personality and Social Psychology, 71, 450-463.

Markman, K. D., Gavanski, I., Sherman, S. J., \& McMullen, M. N. (1995). The impact of perceived control on the imagination of better and worse possible worlds. Personality and Social Psychology Bulletin, 21, 588-595.

McFarland, C., \& Ross, M. (1982). Impact of causal attributions on affective reactions to success and failure. Journal of Personality and Social Psychology, 43, 937-946.

McGuire, W. J. (1964). Inducing resistance to persuasion: Some contemporary approaches. In L. Berkowitz (Ed.), Advances in experimental social psychology: Vol. 1 (pp. 191-229). New York: Academic Press.

Miller, D. T. (1976). Ego involvement and attributions for success and failure. Journal of Personality and Social Psychology, 34, 901-906.

Plous, S. (1991). Biases in the assimilation of technological breakdowns: Do accidents make us safer? Journal of Applied Social Psychology, 21, 1058-1082.

Roese, N. J. (1997). Counterfactual thinking. Psychological Bulletin, 121, 133-148.

Roese, N. J., \& Olson, J. M. (1993). Self-esteem and counterfactual thinking. Journal of Personality and Social Psychology, 65, 199-206.

Roese, N. J., \& Olson, J. M. (1996). Counterfactuals, causal attributions, and the hindsight bias: A conceptual integration. Journal of Experimental Social Psychology, 32, 197-227.
Sanna, L. J. (1996). Defensive pessimism, optimism, and stimulating alternatives: Some ups and downs of prefactual and counterfactual thinking. Journal of Personality and Social Psychology, 71, 10201036.

Sanna, L. J., \& Turley, K. J. (1996). Antecedents to spontaneous counterfactual thinking: Effects of expectancy violation and outcome valence. Personality and Social Psychology Bulletin, 22, 906919.

Sherman, S. J., \& Gorkin, L. (1980). Attitude bolstering when behavior is inconsistent with central attitudes. Journal of Experimental Social Psychology, 16, 388-403.

Tetlock, P. E. (1998). Close-call counterfactuals and belief-system defenses: I was not almost wrong but I was almost right. Journal of Personality and Social Psychology, 75, 639-652.

Tetlock, P. E., \& Visser, P. S. (2000). Thinking about Russia: Plausible past and probable futures. British Journal of Social Psychology, 39, 173-196.

Tesser, A., Martin, L., \& Mendolia, M. (1995). The impact of thought on attitude extremity and attitude-behavior consistency. In R. E. Petty, \& J. A. Krosnick (Eds.), Attitude strength: Antecedents and consequences (pp. 73-92). Mahwah, NJ: Erlbaum.

Wells, G. L., \& Gavanski, I. (1989). Mental simulation of causality. Journal of Personality and Social Psychology, 56, 161-169.

Wright, P. (1975). Factors affecting cognitive resistance to advertising. Journal of Consumer Research, 2, 1-9. 